\title{
SELFIES AND SELF-FictionS
}

Calibrating Co-presence in and of 'the Field'

Liana Chua

\begin{abstract}
Through what fictions do anthropologists become co-present in 'the field'? And what happens when 'the field' becomes co-present in anthropologists' lives? In this article, I reflexively contrast two experiences of fieldwork connectedness: first, the changes to my interactions with Bidayuh villagers in rural Borneo since 2003, and, second, my recent engagement with the social media-scape of orangutan conservation. Both examples shed light on the methodological and ethical questions about the self-fictions through which anthropologists create our presence in the field-and how those fields assert their presence beyond our research projects. Recent technological developments, I suggest, thus underscore fundamental questions of how to calibrate fieldwork relations and where to locate the boundaries and openings of the anthropological self-a process that we cannot entirely control.
\end{abstract}

Keywords: anthropological self, Borneo, co-presence, fictions, orangutan conservation, social media

In January 2005, a third of the way through my PhD fieldwork in Sarawak, Malaysian Borneo, my UK-based boyfriend and I had a messy break-up. Frazzled, furious, heartbroken, I lay low, figuring out what to do next. By then, I had already told my interlocutors-indigenous Bidayuh villagers-about this person, showing them his picture, saying nice things about him, and even brandishing my not-quite-silver, not-quite-engagement ring. As far as my acquaintances were concerned, I had a fiancé in England whom I would marry when I returned.

Our putative engagement was a fiction that-partly on the advice of Sarawakian friends-I had devised to protect myself from amorous advances during fieldwork. Given that we had been together nearly five years, it did not feel a 
huge stretch-especially if it made fieldwork safer. As the villagers were devout Christians, I thought that being 'engaged' would make me look more respectable. But now, afraid of losing respectability, I did not tell anyone about our split (although I no longer mentioned my ex-boyfriend). To ward off unwanted attention, I continued wearing the ring. This fiction slipped only when I drove my battered little car out of the village to the city, Kuching, where some people knew about my sad love life (or lack thereof). All this continued until the end of my main fieldwork stint in late 2005.

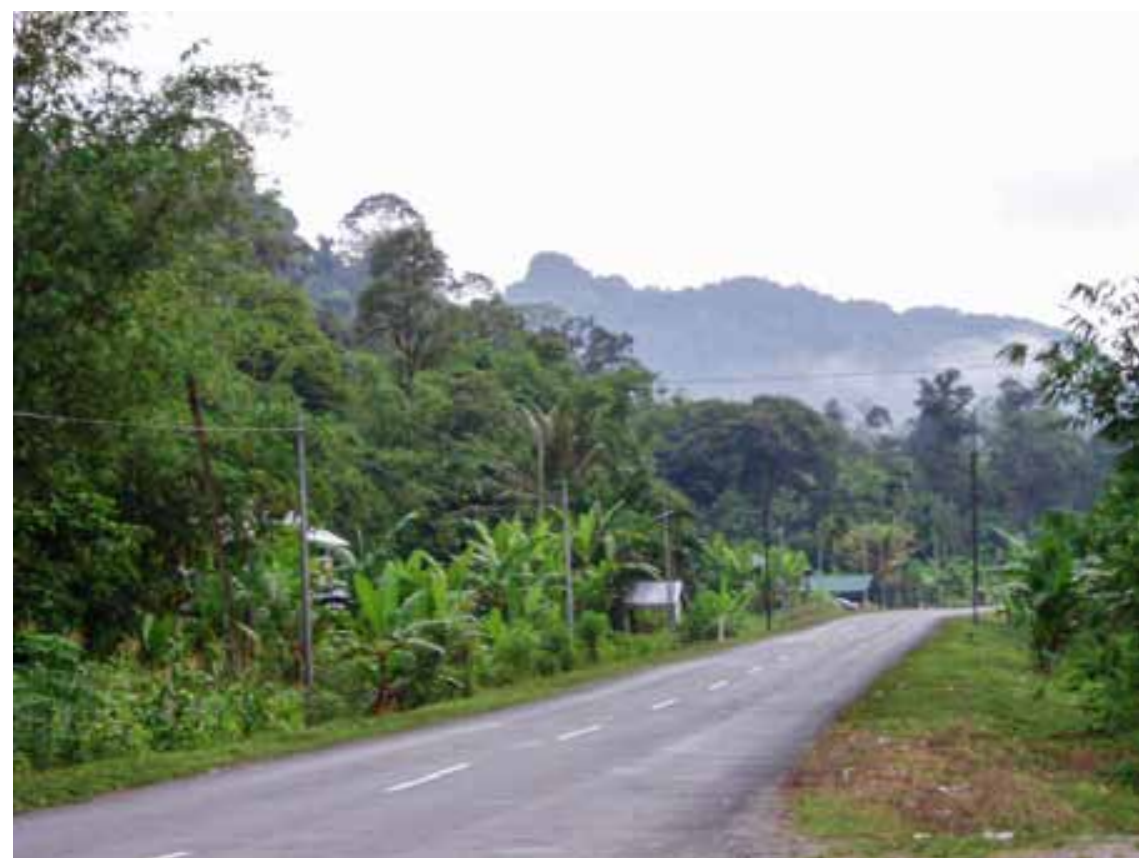

FigurE 1: The road out of the village, 2004. Photograph ${ }^{\circledR}$ Liana Chua

Had my break-up happened in 2015 rather than 2005, it would have been impossible to keep quiet. My capacity to sustain my fictive engagement during my $\mathrm{PhD}$ was tied to my ability to remove myself-not completely, but quite effectively-from a village that had virtually no telecommunications. Once out of the village, I was not easily contactable by the people with whom I spent most of my days. Since then, however, the situation has changed drastically. Telecommunications masts have mushroomed across the region, together with mobile phones, pre-paid SIM cards, and social media platforms-particularly Facebook and WhatsApp. Today, Facebook is the primary medium through which my Bidayuh acquaintances and I keep in touch and remain present in each other's lives. 
In this article, I draw reflexively on my long-term work with Bidayuhs and recent research on orangutan conservation to explore the implications of 'staying connected' for anthropologists' co-presence (Chua 2015) in 'the field'. The need for new "recombinations of 'home' and 'field'” is highlighted by Günel et al. (2020) in their manifesto for "patchwork ethnography," which refers to "ethnographic processes and protocols designed around short-term field visits, using fragmentary yet rigorous data, and other innovations that resist ... fixity, holism, and certainty." Riffing on this, I suggest that we can also think productively with the notion of the patchwork ethnographer-a figure composed of different parts that move constantly in and out of view, while sustaining multiple fictions and relations. Such a figure, I argue, invites us to extend our reflexive lenses beyond the individual anthropologist toward the networks and relational dynamics in which she is inevitably entangled, and which she can only partially control.

\section{Co-presence and Boundaries on Facebook}

In 2005, getting mobile phone reception required driving to the nearest townat which point a few weeks' worth of voice and text messages would flood my Nokia 6610. That chorus of beeps always marked my physical, psychological, and social removal from the village. Driving away, I now realize, was a form of self-care-a means of making space to be a different person from the adoptive daughter, 'student of culture', photographer, and foreign prestige object that I was in the village.

Such physical removability was instrumental in shaping the boundaries of 'the field' and 'fieldwork' during my PhD. Although the ideal of the bounded field site had, by then, been fairly comprehensively dismantled (e.g., Marcus 1995), I could still (just about) draw a rough boundary between my villagebased anthropological self and the rest of my life outside it. However, the extension of mobile phone coverage to the region starting in late 2007 and the widespread adoption of smartphones and Facebook from the early 2010s changed all that.

As Daniel Miller et al. (2016) have written about social media elsewhere, Facebook has become embedded in everyday Bidayuh sociality; people are conversing, sharing material with each other, and engaging with the wider world through it. In this capacity, Facebook has simply become part of 'the field'albeit one in which others, including the village diaspora and faraway ethnographers, can participate from a distance. All this has had implications for both my research and my co-presence in the lives of my Bidayuh acquaintances.

First, social media interactions have changed the temporalities of staying connected. After my PhD fieldwork, I would get bursts of news or messages 
every few months through return field trips or (in the post-mobile phone reception, pre-smartphone period) long-distance telephone calls and SMSs. By contrast, being connected on Facebook means constantly being in the loopand being expected to be in the loop-about births, deaths, accidents, and other events. Moreover, connectedness runs both ways. Because I do not keep separate personal and professional Facebook accounts, my village friends know plenty about my personal life from my posts-including things that would never have entered the orbit of our regular fieldwork conversations.

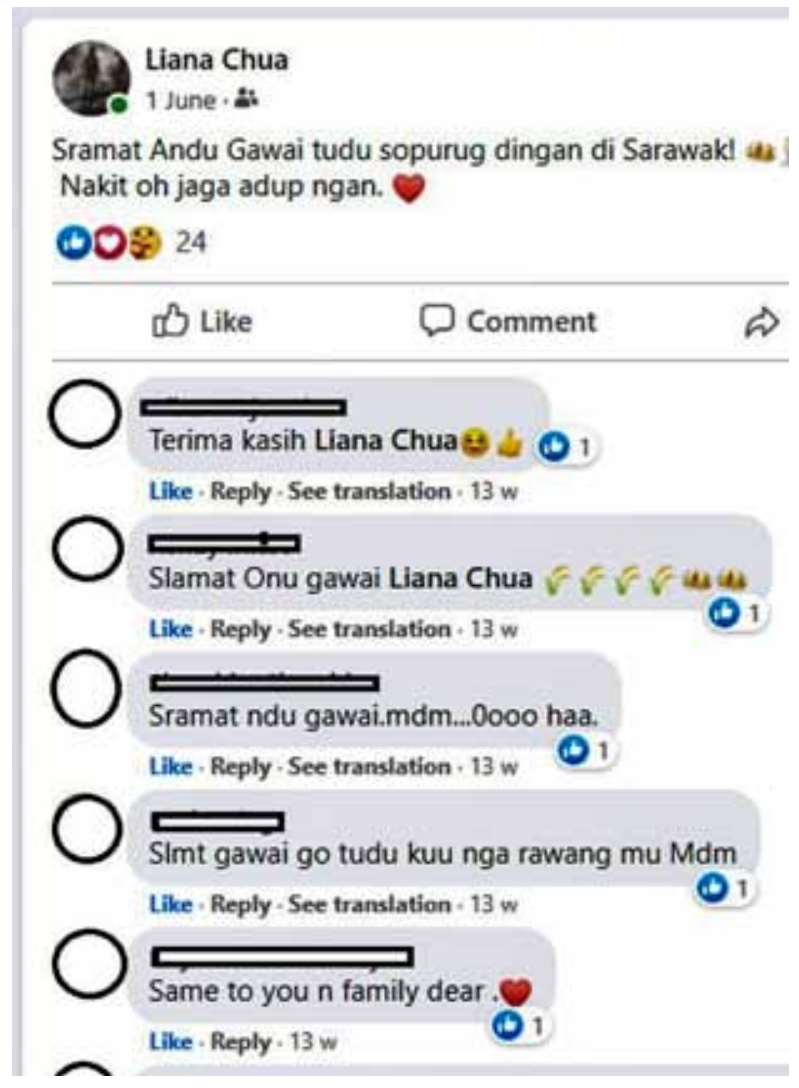

FigURE 2: Screenshot of my Facebook post wishing my Bidayuh friends a happy harvest festival, 2020

Such two-way access also inflects the dynamics of my knowledge practices. During and after my PhD, I initiated physical and epistemological 'returns' to the village-through fact-checking; discussing my ideas, analyses, and drafts with people; and depositing publications, audio-visual recordings, and other documentation with relevant parties. Many older villagers saw these as physical 
manifestations of what they described as my obligation to tell the world about their lives and village, as well as to store (nyikŭn) old knowledge so it would not be lost (mănyap). By contrast, my relationship with some younger Bidayuhsmost of whom are at least conversant in English-is marked by their interest in reading and responding to my work. Some give me feedback and answer queries using Messenger; others follow my publication updates on Facebook, requesting electronic copies and posting comments. Last year, I had a pleasant surprise when someone who was a child during my PhD tagged me in a screenshot of his college assignment in which he cited my book on Christian conversion, saying that he was proud of the work I had done in his village.

These nascent Facebook interactions have, thus far, been positive. However, they also mark a still unfolding shift in my practices of knowledge production and circulation. When the son of the village's last ritual chief Facebook-tagged me in a photograph of himself and other villagers watching the DVD of a ritual that I had made in 2005 and gifted to his father, he visually invoked that older dynamic of reciprocity and preservation. Conversely, what emerges in my Facebook interactions with younger generations is closer to a dynamic of responsivity melded with accountability. Undergirded by the algorithmic, participatory affordances of social media, it is rooted in a shared awareness of the readers' immediate capacity to react, as well as the publicness of our interactions-the fact that our mutual village acquaintances can also see those exchanges.

Such digital visibility can spawn other complications. Selfies taken with village friends during my trips, for instance, have sometimes been spotted on Facebook by others, who asked why I had not visited them too. And some years ago, a village church elder tagged me in a Facebook fundraiser run by the regional parish church, which was asking for large one-off donations to their new building fund. By tagging me as a relatively rich benefactor in full view of the parish church (whose priests I knew) and other village acquaintances (who often half-joked about all Singaporeans like myself being rich), the Catholic elder made a public, very effective moral claim on my association with and obligation to the village. Staying connected had, I realized, opened up a new arena of 'ethnographic exposure' (High 2010) and performativity from which I could not remove myself. A few months later, I handed over my donation to the parish church. This pleased my village acquaintances, who saw me as having fulfilled my Catholic, Singaporean, adopted anthropologist duty.

This, however, brings me back to ethnographic fictions-and a confession. Although I had a Catholic upbringing, I am not religious, and had not been for a while when I began my PhD. During fieldwork, however, I was adopted by a Catholic family and participated in every aspect of Catholic life, while also attending Anglican and evangelical services. Even though I never expounded on my (a)religious leanings, I was classed as Catholic because when I was in the village-where there was little conceptual space for the notion of not 
having a religion-I mainly did Catholic things. As I explain elsewhere (Chua 2012), Bidayuh Christianity is highly praxiological rather than rooted in an inner state of assent. What matters is 'doing things right', which was what I tried to do during fieldwork.

Over time and without premeditation, Catholicism thus evolved into a relational interface that-like my engagement ring, nationality, and status as adopted daughter and student of culture-helped situate me within existing networks. It simply became a part of my village self that-for a while, at least-I could leave in the field. But this is not possible in the porous world of Facebook, where my personal and professional lives bleed into each other. Today, I am more careful with my posts: I seldom mention religion, and engage politely but not religiously with the Christian memes and viral prayers that come my way. Without the option of physical removal, I thus try to lay down digital boundaries by curating my Facebook self and interactions to fit the relations and expectations that have become increasingly co-present on my timeline.

\section{Learning to Be(come) Present on Twitter}

I would now like to turn to a different social media platform and 'field' - namely, Twitter, and my research on the social, political, moral, and affective dimensions of orangutan conservation. I currently lead two projects that involve both ethnographic analyses of orangutan conservation and collaborations with orangutan conservationists and organizations.

Twitter is an important part of orangutan conservation, serving as a field of knowledge production, interaction, and mobilization (Chua 2018). Consequently, I too have learned to use it as a research method, a form of engagement, and an ethnographic object. Like \#AnthroTwitter, orangutan conservation on Twitter is lively but volatile-filled with strong convictions, personalities, and arguments. And the challenge that this field poses is how to become present in the right way.

Here, however, another confession is due. While I like orangutans and do not want them to go extinct, I do not have a special interest in them. What drew me to this research are people-particularly rural communities in Borneo and Sumatra and their experiences of conservation, along with attendant questions of power, legitimacy, and difference. This, however, is not something that I broadcast too loudly or frequently on Twitter. While making it clear that I am a social anthropologist, I also constantly calibrate the relations between different parts of my anthropological self in my orangutan research.

For many orangutan conservation scientists, my research is generally seen as a plus-a source of information and insight that can shed light on the human complexities they have to deal with. With them, I can be fairly open about 


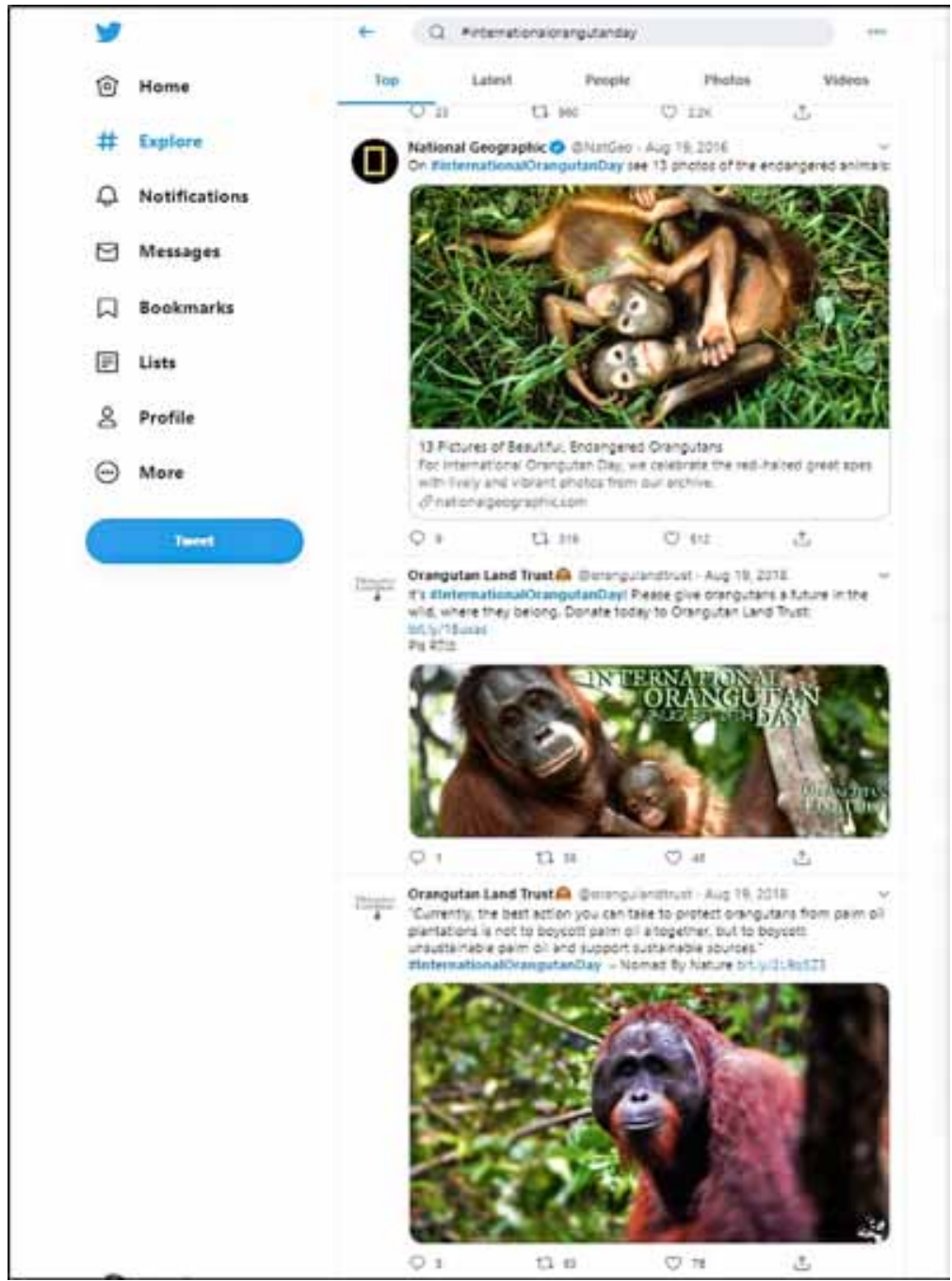

FIGURE 3: Screenshot of the Twitter search results for \#InternationalOrangutanDay, which unfolds annually across social media

where my interests lie. But when I interact with orangutan charities, photographers, or supporters, I keep my research trajectory in the background while foregrounding orangutans and conservation. My priority is eliciting others' points of view, not broadcasting my own, and a mutual interest in orangutans is a productive means of sustaining this dynamic. This has important implications for the tenor and content of our interactions. If, for example, my interlocutors criticize rural Borneans for harming orangutans, casting them as ignorant or 
cruel, I push back-but not as strongly as I might otherwise, so as not to shut down the conversation. This is easier online, when I can pause to think or step back from a social media exchange. However, if Twitter has given me the relative freedom and removability to curate my online persona and activities, in-person research can sometimes prove trickier.

This became palpable when I attended a protest in the United Kingdom against a looming infrastructural threat to the habitat of a critically endangered orangutan population in Indonesia. During the event, I moved around, grabbing snatches of conversation with protesters and passers-by, occasionally mentioning my research but largely just chatting about orangutans. Strikingly, our exchanges centered not on the specific threat posed by this infrastructural project or the ecosystem around which the protest revolved, but on a generic, familiar set of motifs that shape popular orangutan conservation narratives in the UK (Chua 2018): charismatic orphaned orangutans, the problem of palm oil, and the devastation caused by deforestation, with rural communities occasionally invoked as suffering subjects (Robbins 2013) or perpetrators of environmental harm.

Casually demonstrating our acquaintance with these motifs allowed us to forge a momentary alliance in which we assumed shared, taken-for-granted subjectivities as orangutan lovers who already knew what was at stake-no explanation needed. Handing out leaflets and holding a placard, and fueled by genuine concern for the fate of this particular population, I slipped easily into this persona. However, there were moments when my self-fiction faltered. One was when a passer-by stopped, scrutinized our signs, and then declared loudly: “Save humans first! Give people food, housing, water-don't just talk about saving animals!" The leader of the protest quickly intervened and argued that stopping the infrastructural project and saving the forest was also about saving humans. The nearby protesters rallied behind him. After a while, I realized that I had been nodding vigorously at everything the passer-by said, and that a couple of people were giving me strange looks. In that moment, another part of my professional self had punctured the self-fiction that legitimated my place in this momentary alliance. Without the temporal and digital removability afforded by Twitter, I slid back into persona, sensing that if I too openly sided with the passer-by, my co-presence in the protest could be compromised.

\section{Conclusion}

Reflecting on her research in two contexts of collective violence in India, Chitralekha (2017: 157) describes her fieldwork interactions as "a series of dramaturgical encounters ... where both the subjects of my study and I continuously anticipated, postured, and play-acted to the (imagined) expectation of the other" (see also Borneman 2009: 238; High 2010). This depiction succinctly captures 
how anthropological interactions routinely exceed simple binaries of 'right' and 'wrong', 'truth' and 'falsity'. Anthropological self-fictions, I suggest, play an important role in these processes as equivocating devices that enable connection and interaction across what can be quite different grounds and agendas.

By this, I am not advocating that anthropologists deliberately deceive our interlocutors or conduct research on false premises. Rather, I am arguing for the need to have more honest, nuanced conversations about how anthropologists become and stay co-present in the field, and the constitutive importance of (self-)fictions in these processes. This entails recognizing the intensely messy, complex, and ever-evolving nature of relations in the field-as well as our interlocutors' own subjectivity and agency in interpreting, responding to, and shaping our presence(s). As Anna Tsing (1993) and Peter Metcalf (2002) reveal through intimate portraits of their closest Bornean interlocutors, our fieldwork encounters are never solely about us or our work. Anthropological research cannot be bracketed off from-and is indeed often drawn into-other relations, power dynamics, fictions, projects, and fantasies (High 2010).

Crucially, these are not processes that anthropologists can fully control. While it is vital to critically interrogate anthropologists' own power and privilege, it is equally important to attend to the micro-politics and dynamics of particular fieldwork contexts-whose specificities risk being occluded by a rigid binary between 'powerful' anthropologist and 'powerless' research subjects. Thinking through ethnographic self-fictions reminds us that be(com)ing anthropologically present in 'the field'-any field-necessarily means establishing and negotiating our co-presence with others (Chua 2015). It means partitioning and curating aspects of the ethnographic self-or having it curated by others-so as to become legible, legitimate, relatable to.

This is where we might return to the figure of the patchwork ethnographer. Like 'patchwork ethnography', this figure defies holism and fixity-in this case, of the anthropological self-calling attention instead to how its different parts are variously invoked, suppressed, removed, and reworked by both the anthropologist and others. Few people, after all, bring their whole, unedited selves (if these even exist) to social interactions, and ethnographic encounters are no different. Viewed through this lens, anthropological co-presence cannot be rooted to a singular authentic self; it can only emerge out of the give and take of interactions in the field.

As my contrast between physical removability from the village and removability via Twitter suggests, however, these patchwork-y processes are not necessarily moored to specific fields or fieldwork modalities. Rather, I suggest that they point us to some fundamental concerns that are amplified by but not unique to digital media: How do we, or others, calibrate the openings, boundaries, and constituents of our selves? How can we think about anthropological co-presence beyond well-worn ethical ideals of connection, reciprocity, 
being-with, and intimacy? How, conversely, might we do productive work with removal, refusal, distancing, and disconnection (see also Coleman 2009)? While this collection's focus on connections pushes us to rethink our definitions of 'the field', our methods and ethics, and issues of power and accountability, it also invites us to interrogate what connectedness itself entails. More than using 'staying connected' as a portal to bigger questions, perhaps anthropologists should also be interrogating connectedness as a social, methodological, and ethico-political problem, in which our 'patchworked' selves and self-fictions are inevitably implicated.

\section{Acknowledgments}

The orangutan conservation-related research featured in this article is funded by a Brunel University BRIEF Award and European Research Council Starting Grant No. 758494. I am grateful to the panelists, discussants, and audience of the EASA panel in which this article originated for their thoughtful and insightful comments. Above all, I am indebted to my Bidayuh interlocutors, with whom I continue to navigate various forms of co-presence and fictions.

Liana Chua is a Reader in Anthropology at Brunel University London. She has worked with an indigenous group in Malaysian Borneo since 2003, looking initially at religious conversion and ethnic cultural politics, and later at development, resettlement, and environmental transformation. She currently leads the ERC-funded project "Refiguring Conservation in/for 'the Anthropocene': The Global Lives of the Orangutan," which explores the social, political, affective, and aesthetic dimensions of orangutan conservation. Her other research interests include visual and material anthropology, anthropology of the body, and anthropological knowledge practices and politics. E-mail: liana.chua@ brunel.ac.uk 


\section{References}

Borneman, John. 2009. "Fieldwork Experience, Collaboration, and Interlocution: The 'Metaphysics of Presence' in Encounters with the Syrian Mukhabarat.” In Borneman and Hammoudi 2009, 237-258.

Borneman, John, and Abdellah Hammoudi, eds. 2009. Being There: The Fieldwork Encounter and the Making of Truth. Berkeley: University of California Press.

Chitralekha. 2017. "Why Does the Subject Speak? Prejudgement in Fieldwork with Naxalites and Hindu Rioters." Journal of the Royal Anthropological Institute 23 (1): 155-174.

Chua, Liana. 2012. The Christianity of Culture: Conversion, Ethnic Citizenship, and the Matter of Religion in Malaysian Borneo. New York: Palgrave Macmillan.

Chua, Liana. 2015. "Troubled Landscapes, Troubling Anthropology: Co-presence, Necessity, and the Making of Anthropological Knowledge." Journal of the Royal Anthropological Institute 21 (3): 641-659.

Chua, Liana. 2018. “Too Cute to Cuddle? 'Witnessing Publics' and Interspecies Relations on the Social Media-scape of Orangutan Conservation." Anthropological Quarterly 91 (3): 873-903.

Coleman, Leo. 2009. "The Obligation to Receive: The Countertransference, the Ethnographer, Protestants, and Proselytization in North India.” In Borneman and Hammoudi 2009, 113-150.

Günel, Gökçe, Saiba Varma, and Chika Watanabe. 2020. “A Manifesto for Patchwork Ethnography.” Member Voices, Fieldsights, 9 June. https://culanth.org/ fieldsights/a-manifesto-for-patchwork-ethnography.

High, Holly. 2010. "Ethnographic Exposures: Motivations for Donations in the South of Laos (and Beyond)." American Ethnologist 37 (2): 308-322.

Marcus, George E. 1995. "Ethnography in/of the World System: The Emergence of Multi-Sited Ethnography.” Annual Review of Anthropology 24: 95-117.

Metcalf, Peter. 2002. They Lie, We Lie: Getting on with Anthropology. London: Routledge.

Miller, Daniel, Elisabetta Costa, Nell Haynes, Tom McDonald, Razvan Nicolescu, Jolynna Sinanan, Juliano Spyer, Shriram Venkatraman, and Xinyuan Wang. 2016. How the World Changed Social Media. London: UCL Press.

Robbins, Joel. 2013. "Beyond the Suffering Subject: Toward an Anthropology of the Good." Journal of the Royal Anthropological Institute 19 (3): 447-462.

Tsing, Anna Lowenhaupt. 1993. In the Realm of the Diamond Queen: Marginality in an Out-of-the-Way Place. Princeton, NJ: Princeton University Press. 